\title{
Empathy \& Emotional Expression: Implications of Psychopathy \& Immorality
}

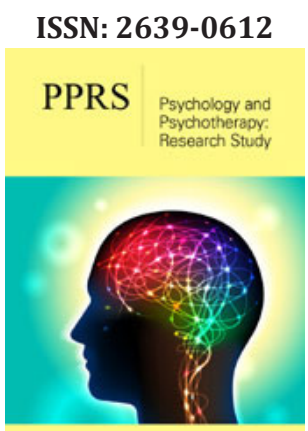

*Corresponding author: Department of Psychology, USA

Submission: 眥 June 19, 2019

Published: 俔 November 06, 2019

Volume 2 - Issue 5

How to cite this article: Katelyn Rinker. Empathy \& Emotional Expression: Implications of Psychopathy \& Immorality. Psychol Psychother Res Stud. 2(5). PPRS.000550.2019.

DOI: 10.31031/PPRS.2019.02.000550

Copyright@ Katelyn Rinker, This article is distributed under the terms of the Creative Commons Attribution 4.0 International License, which permits unrestricted use and redistribution provided that the original author and source are credited.

\author{
Katelyn Rinker* \\ Department of Psychology, USA
}

\section{Mini Review}

Does sympathizing with the emotions of others influence the ability to make moral choices? The role of emotion in moral judgment is so prominent that the lack of emotion indicates immoral attitudes. Researchers from Georgetown University's Department of psychology admit that individuals with psychopathic tendencies may be unable to recognize distress or fear in others, which may lead to the assumption that they are more likely to cause physical harm [1]. But everyone in a particular category for a mental disorder cannot be labeled as dangerous due to the drastic differences between some individuals. Georgetown University clarified that there were not any mental disorders that cause immoral beliefs actions [1]. The capacity that an individual may have for violence depends on multiple factors, such as personality traits and environmental situations. However, the link between apathy and immorality may be important to understand due to the theory that emotions play a major role in moral judgment.

Another scientific journal known as Personality and Individual Differences tested this theory in their article titled "The Ends Justify the Meanness," where they focus on the moral judgments in psychopaths [2]. They admit that psychopaths are able to "understand morality as well as the general population but simply do not care," which sparked the inspiration for a research study involving emotional judgments of morality [2]. They analyzed 316 college students by asking them questions about utilitarian decisions, such as questions involving empathy, boldness, self-centered impulsivity, aggression, and fearless dominance [2]. Utilitarianism was defined as the needs of one individual can be sacrificed or tolerated to save the majority of the population. The utilitarian approach is a term that involves both an internalized sense of morality and emotional expression of those beliefs. When faced with a moral dilemma involving life-death situations, the journal known as Physiology \& Biology explains that there are two choices, which include "letting some people die (non-utilitarian) vs. killing one person to save more people (utilitarian)" [3]. These values of right or wrong choices may depend on a mixture of individualism and mental health status.

The American Journal of Psychology also centered a study on testing moral choices through a utilitarian approach, which was conducted by the curtesy from the University of Wisconsin and Montana State University [4]. They observe 140 college students who have all completed a college class on introductory psychology, along with "appropriate" or "inappropriate" answers to three moral dilemmas [4]. The two universities claim that the "choice to save a group and kill one is considered a utilitarian judgment in which costs and benefits of an action are weighed and the action that produces the highest benefit to cost ratio is considered the right action" [4]. They concluded that most of the research participants would rather intentionally kill an individual so save a small group of people, which suggests that mass murder is not morally appropriate [4]. The safety of the entire population may be more important than losing one person, according to the opinions of college students from this study.

The Journal of Criminal Justice echoes this same idea by testing 302 college students on responses to 15 moral dilemmas, along with an assessment that measures psychopathy [5]. The Psychopathic Personality Inventory that involves 56 questions on internalizing feelings 
of anxiety or depression, in addition to externalizing behaviors like interpersonal dominance, aggression, impulsivity, and hostility [5]. They found concluded that a powerful motivator for immoral actions involved aggressive behaviors [5]. These results might actually indicate that emotions were needed to make immoral decisions. As anger has been known to be an extremely negative emotion, it may be safe to make the assumption that all individuals with psychopathic personality traits do not always make immoral judgments. As with many behaviors, moral actions differ among various individuals, regardless of their mental state. Everyone within a certain mental disorder cannot be labeled as immoral due to their individual differences.

In contrast to previous studies mentioned in this paper, the next several journal findings focus on individuals with psychopathic traits, which is commonly referred to as antisocial personality disorder. A journal known as Social Neuroscience agreed that individual differences account for the likelihood of displaying immoral behavior, which they determined by testing 265 antisocial participants on beliefs about motivation, empathy, sensitivity, concern, blame and moral rules [6]. Another journal called Scientific Reports echoed this same thought by claiming that "evidence suggests that individual differences emerge in the distinct psychological processes involved in moral judgment, such as emotional reaction, controlled cognition and mental-state reasoning". A unique individual's emotional responses impact the ability to make moral choices.

Immorality due to a lack of empathy may greatly impair one's ability to recognize emotion. This concept of differing perceptions may include the distinguishing features of facial expressions and their accompanying emotions. The Journal of Personality admits that "facial expressions can thus trigger robust emotional reactions in humans, such as feelings of threat, personal distress, and empathy" [7]. They conducted a small study on 18 research participants and half of this group were diagnosed with antisocial personality disorder, or psychopathy. They were asked to differentiate pictures of faces that were happy, fearful, or neutral, which concluded that the antisocial group was significantly unable to correctly identify emotions due to a reduction in activity of the fusiform gyrus [7]. The fusiform gyrus is a section of the brain that is responsible for the accurate perception of human faces. It allows an individual to learn new faces and recognize past ones. The lack of awareness in memorizing facial expressions may cause antisocial individuals to go without the crucial ability to recognize fear or sadness [8]. A journal known as Social Neuroscience studied 80 men from a medium-security prison who competed various psychological tests, including the Wechsler Adult Intelligence Scale, Structured Clinical Interview, and Beck Depression Inventory [8]. Half of the participants were deemed to have psychopathic personality traits. The other 40 men served as a control group. Both groups were asked to watch 64 videos of people who were happy, sad, afraid, and in pain, which showed that the healthy controls were significantly better at distinguishing the correct emotion from looking at fascial expressions [8].

Unemotionality is a key notion of psychopathy and immorality. Antisocial research participants were contrasted with a healthy control group so that moral judgment can be compared between the two groups. Research shows that although psychopathic individuals are able to understand how emotions works, they may not always be able to correctly estimate which emotion is displayed within social interactions [2]. Antisocial individuals may be unable to recognize facial expressions, especially those involving happiness or sadness [8]. A clinical psychologist may consider using other methods of communication, such as relying on words or tone of voice. Despite the negative stigma of psychopathy, the thin line between unemotionality and immorality is actually determined based on unique differences in individualism.

\section{References}

1. Cardinale E, Marsh A (2015) Impact of psychopathy on moral judgments about causing fear and physical harm. A Peer-Reviewed Open Access Journal 10(5).

2. Balash, Falkenbach (2018) The ends justify the meanness: An investigation of psychopathic traits and utilitarian moral endorsement. Personality and Individual Differences 127: 127-132.

3. Sarlo M, Lotto L, Rumiati R, Palomba D (2014) If it makes you feel bad, don't do it! Egoistic rather than altruistic empathy modulates neural and behavioral responses in moral dilemmas. Physiol Behav 130: 127-134.

4. Kortenkamp KV, Moore CF (2014) Ethics under uncertainty: The morality and appropriateness of utilitarianism when outcomes are uncertain. Am J Psychol 127(3): 367-382.

5. Gao Y, Tang S (2013) Psychopathic personality and utilitarian moral judgment in college students. Journal of Criminal Justice 41(5): 342-349.

6. Decety J, Yoder J (2016) Empathy and motivation for justice: Cognitive empathy and concern, but not emotional empathy, predict sensitivity to injustice for others. Soc Neurosci 11(1): 1-14.

7. Cardoso SA, Viding E (2015) Functional neuroscience of psychopathic personality in adults. J Pers 83(6): 723-737.

8. Decety J, Skelly L, Yoder K, Kiehl K (2014) Neural processing of dynamic emotional facial expressions in psychopaths. Soc Neurosci 9(1): 36-49. 